\title{
Factors influencing coronary heart disease mortality: findings from the US National Longitudinal Mortality Study
}

\author{
Siddaiah $\mathbf{R}^{1}$, Johnson $\mathbf{L R}^{2}$ \\ ${ }^{1}$ Dr Rangaswamy Siddaiah, Associate Professor, Department of General Medicine, ${ }^{2}$ Dr Liaquat Roopesh Johnson, \\ Associate Professor, Department of Community Medicine. Both are affiliated with DM Wayanad Institute of Medical \\ Sciences, Wayanad, Kerala, India.
}

Address for Correspondence: Dr.Liaquat Roopesh Johnson, e-mail: liaquat99@gmail.com

\begin{abstract}
Introduction: Globally, mortality due to non-communicable diseases (NCDs) is on the rise. Coronary Heart Disease (CHD) is responsible for a large proportion of preventable cardiovascular mortality. This study aims to determine the factors associated with mortality due to acute and chronic CHD among adults ( $>18$ years). Materials and Methods: A cohort of 2769 adults who died of CHD or hypertension was selected from the public-use dataset of the US National Longitudinal Mortality Study (NLMS). Age, sex, race, marital status, place of residence, health insurance status and employment status were examined for association with acute or chronic CHD mortality. Results: In bivariate analyses all variables were significantly associated with mortality due to CHD. However, in logistic regression analysis only Age (less than 70 years) (p: 0.04) and Race (White) (p: 0.001) reached statistical significance. Conclusion: Age and race are significantly associated with the occurrence of mortality due to CHD in the USA.
\end{abstract}

Key words: National Longitudinal Mortality Study, Preventable mortality.

\section{Introduction}

Non-communicable diseases (NCDs) are responsible for 38 million deaths each year [1,2].42\% of the deaths due to NCDs occur before the age of 70 years, and are considered premature deaths [2]. Most (46\%) of the NCD deaths are attributable to Cardiovascular diseases (CVDs) [1]. In fact, CVDs are the leading cause of death globally, accounting for $31 \%$ of global deaths [3]. $42 \%$ of all CVD deaths are attributable to CHD [3].

Cardiovascular Diseases are the leading cause of death in the United States of America (USA), with 1 in 3 deaths attributable to CVDs. Coronary Heart Disease is responsible for 1 in 7 deaths in the United States, killing one person every 84 seconds [4].

Within the USA, Blacks have the highest cardiovascular disease death rates, followed by Whites and American Indians [5]. Black men and women also have the highest prevalence of Hypertension among all US population groups [5].

Manuscript received $4^{\text {th }}$ April 2016

Reviewed: $16^{\text {th }}$ April 2016

Author Corrected: $25^{\text {th }}$ April 2016

Accepted for Publication $8^{\text {th }}$ May 2016
The number of men and women dying due to cardiovascular disease in the USA in 2013 was similar402851 and 398 086, respectively. Coronary Heart Disease (46.2\%) and Hypertension $(9.0 \%)$ were the leading causes of cardiovascular mortality in the USA in 2013 [5].

Various factors like age, sex and race have been described as influencing the occurrence of cardiovascular disease [5]. However, the influence of these and other socio-demographic/ behavioural factors on mortality due to acute and chronic CHD - the leading cause of CVD mortality- has not been examined. Using data from the National Longitudinal Mortality Study (NLMS), we examined the characteristics of individuals whose death was attributed to CHD or hypertension to determine the modifiable and non-modifiable risk factors associated with such mortality.

\section{Materials and Methods}

The National Longitudinal Mortality Study (NLMS) is a longitudinal data set that is used to examine 
demographic, socio-economic and occupational factors associated with all-cause and cause-specific mortality in the USA [6]. The data is representative of the noninstitutionalized civilian population of the USA. The public-use NLMS (version 5) file consisted of five separate files, each containing individual level data representing a specified duration of follow-up and decade. For this study, we used the file identified as File 11 , which consists of records from the NLMS that are eligible for a maximum follow-up of 11 years, and consists of 1,835,072 individual-level entries. The public-use data set has been carefully manipulated to exclude personal identifiers. After applying suitable filters, a cohort of 2,769 individuals who were $\geq 18$ years, and had died of either hypertension or CHD was obtained. The file contains 43 variables, including age, sex, race, marital status, employment status, place of residence and cause of death. We examined the relationship between the aforementioned variables and death due to CHD or hypertension. For the purpose of analysis, acute and chronic conditions were grouped separately based on the cause of death provided in the original file. Institutional review board approval was not required, as all data were publicly available and the study did not involve human participant interactions.

Data were analysed using $\mathrm{R}$ version 3.2.4 Revised and the package RcmdrPlugin.EZR [7,8]. Bivariate analyses were performed using Independent Samples $t$ Test and $\chi^{2}$ Test. Statistical significance was fixed at the $5 \%$ level. Categorical variables that reached statistical significance on bivariate analyses were included in a logistic regression model for multivariate analysis.

\section{Results}

Of the 2769 individuals who satisfied the inclusion criteria for this study, 1207 (43.59\%) had died of Acute Myocardial Infarction (AMI). Atherosclerotic cardiovascular disease 278 (10.04\%) and other forms of chronic ischemic heart disease $1166(42.11 \%)$ accounted for most of the remaining deaths. Deaths due to Hypertensive heart disease 94 (3.39\%), and hypertensive heart \& renal disease $11(0.40 \%)$ constituted a very small proportion of cases.

Age was recoded into a binary variable with two levels keeping 70 years as the threshold since deaths among persons $<70$ years are considered premature [2]. Further, on performing Independent Samples t-Test, the mean age of those who died due to acute CHD was 67.2 years, as compared to 70.9 years for those who died due to chronic CHD (p: $<\mathbf{0 . 0 0 0 1})$.

The results of bivariate analyses with selected variables are presented in Table 1.

Since acute cardiac events constituted the single largest cause of death, and most such deaths occur within a short time span, it was reordered as the level of interest in logistic regression analysis. The results of logistic regression analysis are presented in Table 2 .

Table 1: Results of Bivariate analyses with selected variables.

\begin{tabular}{|c|c|c|c|c|}
\hline Variable & Level & Acute CHD deaths (n) & Chronic CHD deaths (n) & $\mathrm{X}^{2} \mathrm{p}$ value \\
\hline \multirow{2}{*}{ Age } & $<70$ years & 672 & 580 & \multirow{2}{*}{$<0.0001$} \\
\hline & $\geq 70$ years & 548 & 864 & \\
\hline \multirow{2}{*}{ Sex } & Male & 726 & 740 & \multirow{2}{*}{$<0.0001$} \\
\hline & Female & 494 & 704 & \\
\hline \multirow{2}{*}{ Marital status } & Currently married & 746 & 709 & \multirow{2}{*}{$<0.0001$} \\
\hline & Others & 470 & 729 & \\
\hline \multirow{2}{*}{ Race } & White & 1143 & 1306 & \multirow{2}{*}{0.002} \\
\hline & Others & 77 & 138 & \\
\hline \multirow{2}{*}{ Residence } & Urban & 866 & 1115 & \multirow{2}{*}{0.0001} \\
\hline & Rural & 353 & 325 & \\
\hline \multirow{2}{*}{ Employment status } & Working & 326 & 257 & \multirow{2}{*}{$<0.0001$} \\
\hline & Not working & 893 & 1186 & \\
\hline
\end{tabular}


Table 2: Results of Logistic Regression Analysis.

\begin{tabular}{|l|l|l|l|l|}
\hline \multirow{2}{*}{ Variable } & \multirow{2}{*}{ Odds Ratio } & 95\% Confidence Interval & \multirow{2}{*}{ p value } \\
\cline { 3 - 4 } & & Lower limit & Upper limit & \\
\hline Age [<70 years] & 1.520 & 1.020 & 2.270 & $\mathbf{0 . 0 4 0}$ \\
\hline Sex [Female] & 0.742 & 0.524 & 1.050 & 0.093 \\
\hline Race [White] & 2.230 & 1.340 & 3.700 & $\mathbf{0 . 0 0 1}$ \\
\hline Residence [Rural] & 1.300 & 0.936 & 1.810 & 0.117 \\
\hline
\end{tabular}

From the results of multiple logistic regression it is seen that after adjusting for other covariates, only age and race reach statistical significance. Those aged less than 70 years are 1.5 times more likely to die due to acute CHD than those 70 years or older (p: 0.040). After adjusting for the other covariates in the model, white individuals are 2.2 times more likely to die due to acute CHD than individuals of other races (p: 0.001).

\section{Discussion}

The findings from this study indicate that age is an important factor in death due to acute CHD. This is consistent with the findings of other investigators who have reported an age gradient with occurrence of fatal CHD [9, 10]. However, the increased mortality due to CHD before 70 years' age is a cause for concern as it includes economically active individuals. Male sex as a risk factor for death due to CHD was not found to be statistically significant on multivariate analysis. This is similar to the findings reported by George and colleagues, who suggest that the risk varies from condition to condition, and there are age gradients within conditions [9].

The finding that whites are at greater risk of dying from CHD is contrary to that reported by the American Heart Association [4,5]. This may be the result of an overwhelming proportion of whites in the study data set (91.4\%) compared to blacks $(7.87 \%)$. Due to this the excess risk for blacks might have been negated, resulting in a contradictory finding. Perhaps using comparable proportions of whites and blacks might accurately determine the risk.

Although bivariate analyses indicated rural place of residence increasing the risk of mortality due to CHD, the same failed to reach statistical significance during multivariate analysis. This may be due to the skewed proportions of cases from urban $(74.49 \%)$ and rural $(25.51 \%)$ areas. One would expect people residing in rural areas to experience higher mortality simply on account of their limited access to appropriate health care, and greater income inequality [10].

Although this study benefits from a large cohort, it suffers from some limitations. Firstly, the study is limited by the data set - as are all studies using secondary data. Several variables of interest were unavailable for analyses- like health insurance status, for instance. This study failed to demonstrate the association between CHD mortality and modifiable risk factors as they were not provided in the file. It is possible that using another file from the public-use data set might have yielded different findings. Next, the generalizability is affected by time period- the data were obtained through the 1980s. Lastly, the findings of this study are applicable only to the noninstitutionalized civilian population of the USA.

\section{Conclusion}

Adults between 18 and 70 years' age, and whites are more likely to experience death due to $\mathrm{CHD}$ in the USA.

This paper uses data obtained from the de-identified public use file of the US National Longitudinal Mortality Study (NLMS).

The National Longitudinal Mortality Study is a collaborative effort between the US Census Bureau and the National Heart, Lung, and Blood Institute (NHLBI), National Cancer Institute (NCI), National Institute on Aging (NIA), and the National Center for Health Statistics (NCHS). The views expressed in this paper are those of the authors and do not necessarily reflect the views of the Census Bureau, NHLBI, NCI, NIA or NCHS.

Funding: Nil

Conflict of interest: None.

Permission of IRB: Yes 


\section{References}

1. World Health Organization. WHO web site. [Online].; 2015 [cited 2016 May 4. Available from: www.who.int/mediacentre/factsheets/fs355/en/.

2. World Health Organization. WHO web site. [Online].; 2014 [cited 2016 May 4. Available from: http://apps.who.int/iris/bitstream/10665/148114/1/9789 241564854_eng.pdf?ua=1.

3. World Health Organization. WHO web site. [Online].; 2015 [cited 2016 May 4. Available from: http://www.who.int/mediacentre/factsheets/fs317/en/.

4. American Heart Association. American Heart Association web site. [Online].; 2016 [cited 2016 May 4 Available from: https :// www.heart.org/idc/groups /ahamah public/@wcm/ @ sop /@smd /documents/ downloadable /ucm_480086.pdf.

5. Mozaffarian D, Benjamin EJ, Go AS, Arnett DK, Blaha MJ, Cushman M, et al. Heart Disease and Stroke Statistics- 2016 Update: A Report from the American Heart Association. Circulation. 2016 Jan 26;133(4):e38-e360. doi: 10.1161/CIR.0000000000000350. Epub 2015 Dec 16.

6. Singh GK, Siahpush M. Ethnic-immigrant differentials in health behaviors, morbidity, and cause- specific mortality in the United States: an analysis of two national data bases. Hum Biol. 2002 Feb;74(1):83109.

7. Dean CB, Nielsen JD. Generalized linear mixed models: a review and some extensions. Lifetime Data Anal. 2007 Dec;13(4):497-512. Epub 2007 Nov 14.

8. Kanda Y. Investigation of the freely available easyto-use software 'EZR' for medical statistics. Bone Marrow Transplant. 2013 Mar;48(3):452-8. doi: 10.1038/bmt.2012.244. Epub 2012 Dec 3.

9. George J, Rapsomaniki E, Pujades-Rodriguez M, Shah AD, Denaxas S, Herrett E, et al. How Does Cardiovascular Disease First Present in Women and Men? Incidence of 12 Cardiovascular Diseases in a Contemporary Cohort of 1937360 People. Circulation. 2015;(132): 1320-8.

10. Backlund E, Rowe G, Lynch J, Wolfson MC, Kaplan GA, Sorlie PD. Income inequality and mortality: a multilevel prospective study of 521248 individuals in 50 US states. Int J Epidemiol. 2007 Jun;36(3):590-6. Epub 2007 Mar 15.

\section{How to cite this article?}

Siddaiah R, Johnson LR. Factors influencing coronary heart disease mortality: findings from the US National Longitudinal Mortality Study. Int J Med Res Rev 2016;4(5):685-688.doi: 10.17511/ijmrr.2016.i05.03. 